This item was submitted to Loughborough's Research Repository by the author.

Items in Figshare are protected by copyright, with all rights reserved, unless otherwise indicated.

\title{
Evaluating environmental control system thermal response to degraded operating conditions
}

\section{PLEASE CITE THE PUBLISHED VERSION}

http://dx.doi.org/10.2514/6.2016-1151

\section{PUBLISHER}

(c) American Institute of Aeronautics and Astronautics

\section{VERSION}

AM (Accepted Manuscript)

\section{PUBLISHER STATEMENT}

This work is made available according to the conditions of the Creative Commons Attribution-NonCommercialNoDerivatives 4.0 International (CC BY-NC-ND 4.0) licence. Full details of this licence are available at: https://creativecommons.org/licenses/by-nc-nd/4.0/

\section{LICENCE}

CC BY-NC-ND 4.0

\section{REPOSITORY RECORD}

Childs, Thomas, Andy Jones, Rui Chen, and Angus Murray. 2016. "Evaluating Environmental Control System Thermal Response to Degraded Operating Conditions". figshare. https://hdl.handle.net/2134/20139. 


\title{
Evaluating Environmental Control System Thermal Response to Degraded Operating Conditions
}

\author{
Thomas Childs ${ }^{1}$, Andy Jones ${ }^{1}$, Prof. Rui Chen ${ }^{1} *$ and Angus Murray ${ }^{2}$
}

This paper documents an investigation into the performance and thermal efficiency of an air-cycle Environmental Control System (ECS) artificially injected with common operational failure modes. A two-wheel bootstrap system is taken from an in-service military fast-jet and installed in a bespoke Ground Test Facility (GTF) at the ECS Research Facility, Loughborough University, UK. The failure modes investigated are bleed air blockages in the intercooler and in the low-pressure water extractor, as well as positional inaccuracy in cycle bypass control valves. The full range of degradation in each fault is considered, allowing the quantification of overall system performance degradation. The performance of the system is found to be insensitive to moderate bleed air blockages (up to $80 \%$ by pipe cross-section area), whilst blockages at low pressure are more detrimental to cycle performance than blockages at high pressure. The cycle and/or control system will self-regulate around most degrading-type faults. This particular system is most sensitive to a failure at one bypass valve, where the hardware allows partial redundancy of the valve but the control system does not.

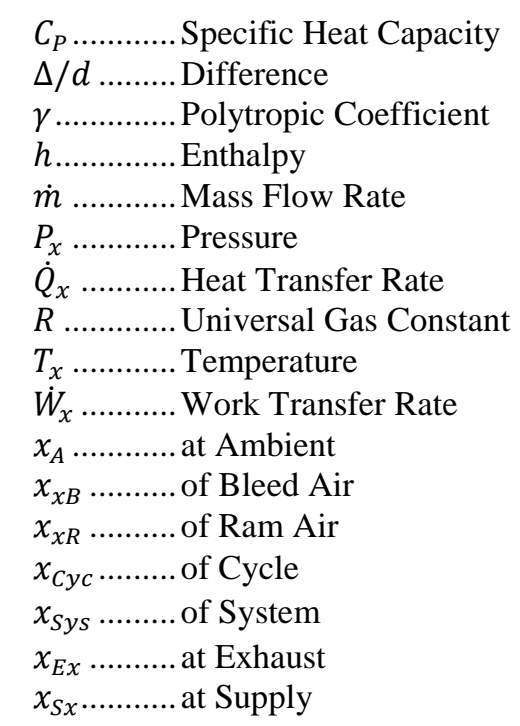

\section{Nomenclature}

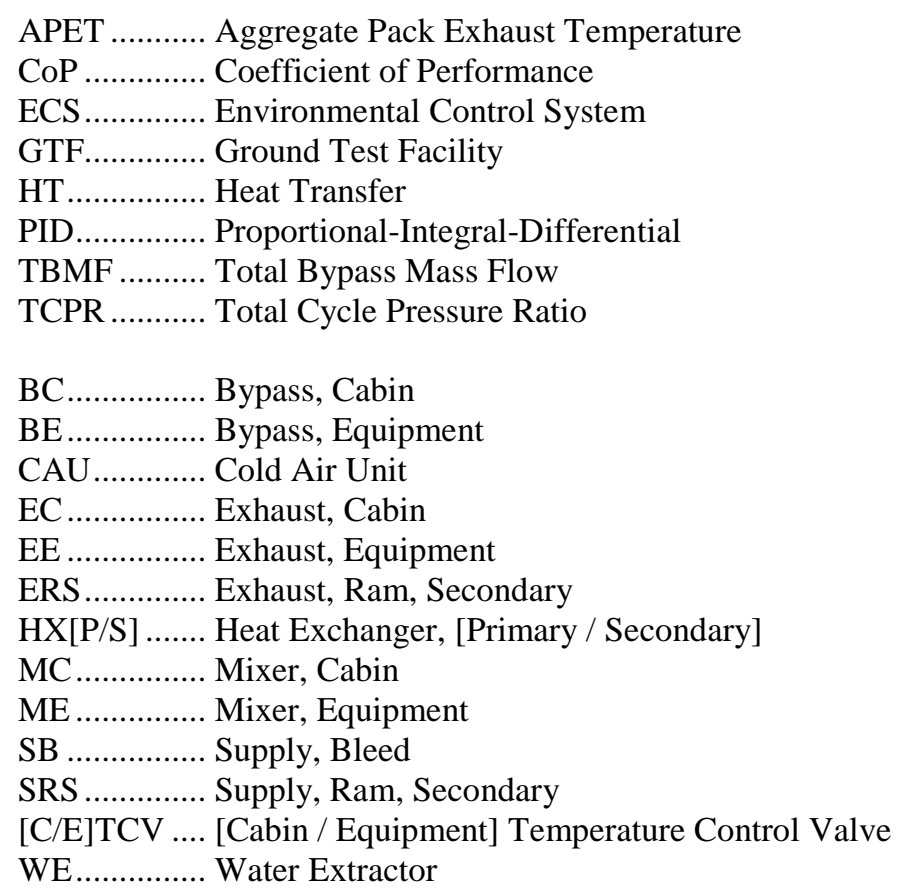

\footnotetext{
${ }^{1}$ Loughborough University, Leicestershire, UK

* Correspondence address: R.Chen@1boro.ac.uk

${ }^{2}$ BAE Systems Military Air \& Information, Warton, Lancashire, UK
} 


\section{Introduction}

$\mathrm{T}$ YPICAL air cycle Environmental Control System (ECS) maintenance and repair regimes can account for downtime of the order 1-5k hrs. per 10k flight hrs. ${ }^{1}$ In addition to the cost of this downtime, the frequency of no-fault-found failures caused by overheating in avionic modules costs the industry over $\$ 10 \mathrm{~m}$ per year in exchanging avionic units. ${ }^{2}$ It is important that any ECS degradation or failures are tracked, so that maintenance can be limited as much as possible to planned routines rather than unscheduled grounding due to unexpected failures.

There is a need within the industry to develop systems for Fault Detection and Isolation (FDI) that are capable of these requirements. Furthermore, it is desirable to integrate methods for FDI into the design process for new systems. $^{3-5}$

The design criteria for the ECS is to account for a wide range of inlet conditions, in terms of engine compressor bleed air and ambient ram air supplies; whilst exhausting to nearly constant cabin-inlet conditions. The 'bootstrap' air-cycle employed by most fast-jet ECS has a tendency to self-regulate to a narrow range of exhaust temperature, due to the relationship between mechanical expansion in the turbine and heat transfer in the mid-cycle heat exchanger. For this reason, it is notoriously difficult to identify reliability issues. ${ }^{1,6-10}$

This investigation aims to further the understanding of the bootstrap ECS by subjecting genuine aircraft hardware to simulated faults. The faults are introduced in a progressive manner, so as to quantify the effect on the system of a performance-degrading reliability issue. The outcomes of the investigation are: to understand the sensitivity of the system to the most commonly observed faults in operation, and to quantify at what level these faults significantly reduce the performance of the whole system.

\section{A. Technical Background}

The range of failures investigated in this report, whilst not exhaustive; covers the most likely causes of system performance degradation in operation. Historic operational data from the donor aircraft shows over $30 \%$ of reported failures to emanate from one of the two cycle bypass valves, with the next-most-common failure modes related to blockages in the system due to unfiltered bleed air. Sand and other particle matter conglomerates in the small air passages of the heat exchangers and coalescing element in the water extractor, especially in humid conditions. Ice is also known to form in the water extractor, usually during transient manoeuvres (when the control system is found to be slow to react), which can cause many problems in addition to a simple bleed air blockage.

The system is operated at conditions which are most problematic for the donor aircraft. The results broadly indicate that the ECS hardware is insensitive to all failures, except those at one bypass valve. This testing was performed with a Ground Test Facility (GTF) rather than through modelling or a flight test for the following reasons:

- An investigation performed with a one-dimensional thermodynamic simulation would demonstrably provide results accurate to those shown in this report. The output from the model would however ultimately be a function of the way the failures were implemented, therefore the engineer would need to know the nature of the system response before the model was built or repurposed for this task.

- A one-dimensional model is unlikely to capture any effects introduced by sensing or control system anomalies; unless these effects are measured, quantified, and deliberately coded into the model. It is also unable to fully evaluate the effect of ambient heat loss and irreversibility introduced to the cycle solely as a result of the failure.

- The failures reproduced during the ground test have been experienced during flight, without significant risk to life or property. It is therefore conceivable that flight tests could be safely conducted in order to diagnose the knock-on effects of these failures. However, an aircraft operator is not able or willing to fly an aircraft with a known fault, and reasonably so.

- The costs associated with instrumenting an existing aircraft design (due to certification) and performing extended flight tests (in order to gather the volume of data required to draw comprehensive conclusions) are prohibitive.

- This investigation is used as an example to demonstrate one method of bringing more 'intelligent' and 'high-value' solutions to aircraft systems design and testing. High-fidelity, high-confidence, repeatable data generated by genuine aircraft equipment operating under faithfully recreated conditions is valuable. Reducing the costs required to obtain this data, especially before designs are committed to production, leads to system design that is more energy- and life-cycle-cost- efficient through greater operational understanding and reduced safety margins. 


\section{Methodology}

\section{A. Hardware}

All of the data presented in this paper was gathered purely from hardware. The ECS used for the task is genuine equipment from a decommissioned current model military fast-jet. Below is a description of the equipment on test and the unique GTF built to house it.

\section{Environmental Control System Architecture}

The system is a bleed-air driven simple two-wheel bootstrap cycle ECS with low pressure water extraction. Two cycle bypass branches are taken upstream of the primary heat exchanger (HXP), regulated by butterfly valves, and reintroduced to the flow downstream of the turbine. A diagram of the system is shown below, where numbered blocks represent instrumentation locations. The component naming convention gives the type and location in order: e.g. SB is Supply Bleed and ERS is Exhaust Ram Secondary. Temperature and pressure readings are taken at each location. Bleed air mass flow is measured at $\mathrm{SB}, \mathrm{EE}$, and $\mathrm{EC}$; whilst $\mathrm{BE}$ and $\mathrm{BC}$ are calibrated for mass flow against pressure drop and TCV position.

The first temperature control valve (TCV) controls turbine-out temperature for application to force-convection cooled avionics (equipment, ETCV, BE). Water extraction is then performed by a coalescing fabric membrane and centrifuge (WE). Finally the second TCV (cabin, CTCV, BC) bypass branch is reintroduced to the flow which is then distributed around the two-man cockpit and three avionics bays.

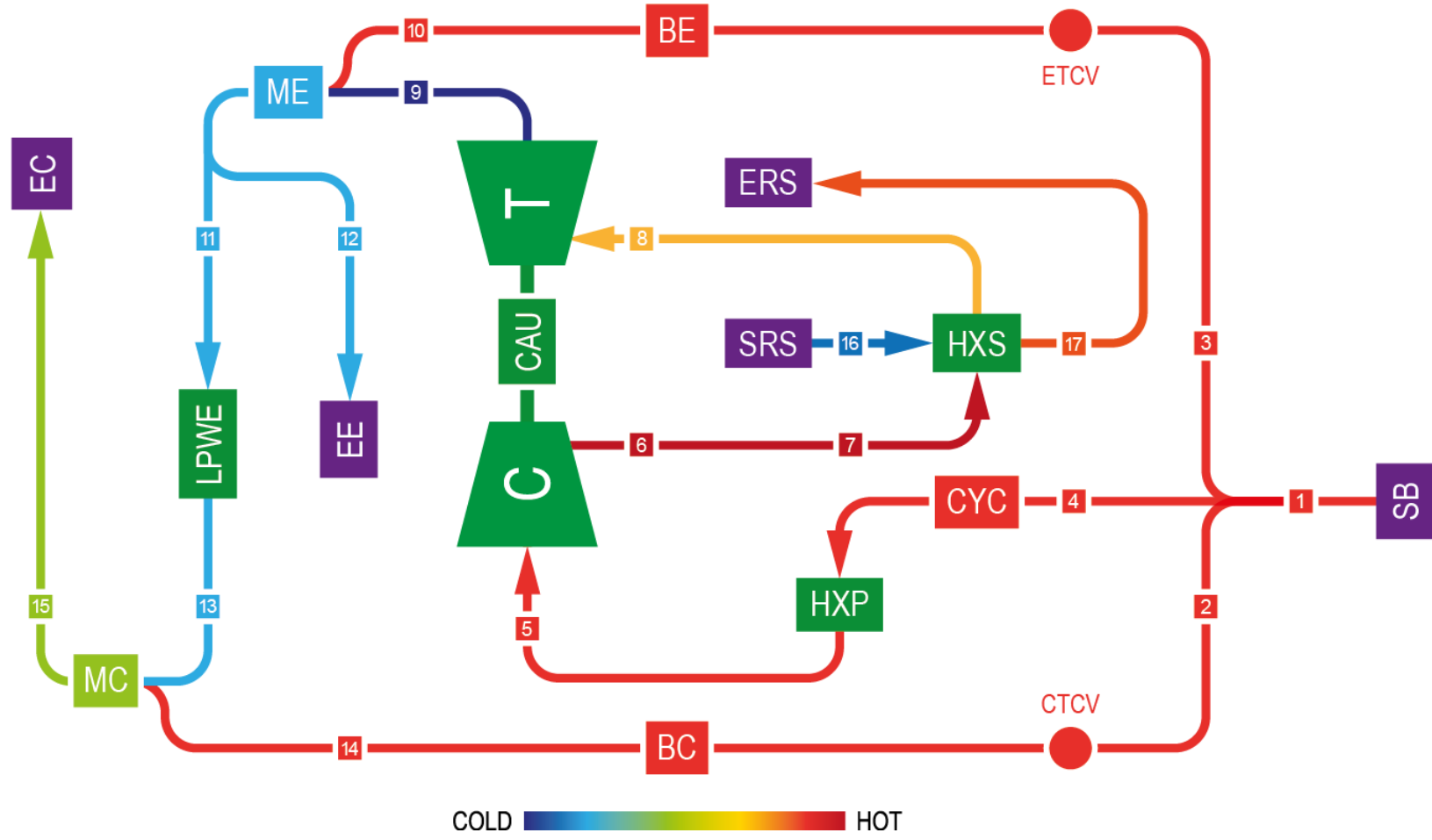

Figure 1. ECS Schematic Instrumentation locations are numbered, thermodynamic components are indicated by a flow direction arrow and green block, boundary conditions by a purple block, and system location labels by a block coloured in accordance with the flow path.

For the purposes of this investigation, analysis is limited to between the Cold Air Unit (CAU) inlet and cabin / equipment inlet (EC, EE / pack exhaust). Only one flight condition is considered throughout, therefore it is possible to consider the performance of HXP to be constant. The experimental setup does not flow any air through HXP, in order to simplify the installation and reduce the facility power demand.

\section{Ground Test Facility Installation}

The figures below show the ECS installed in the test cell. Bleed air heating, test system control and data acquisition are all contained within the mobile installation. The test stand was built out of a necessity to minimise the cost, time and floor space required; whilst maximising the experimental flexibility of the installation. 

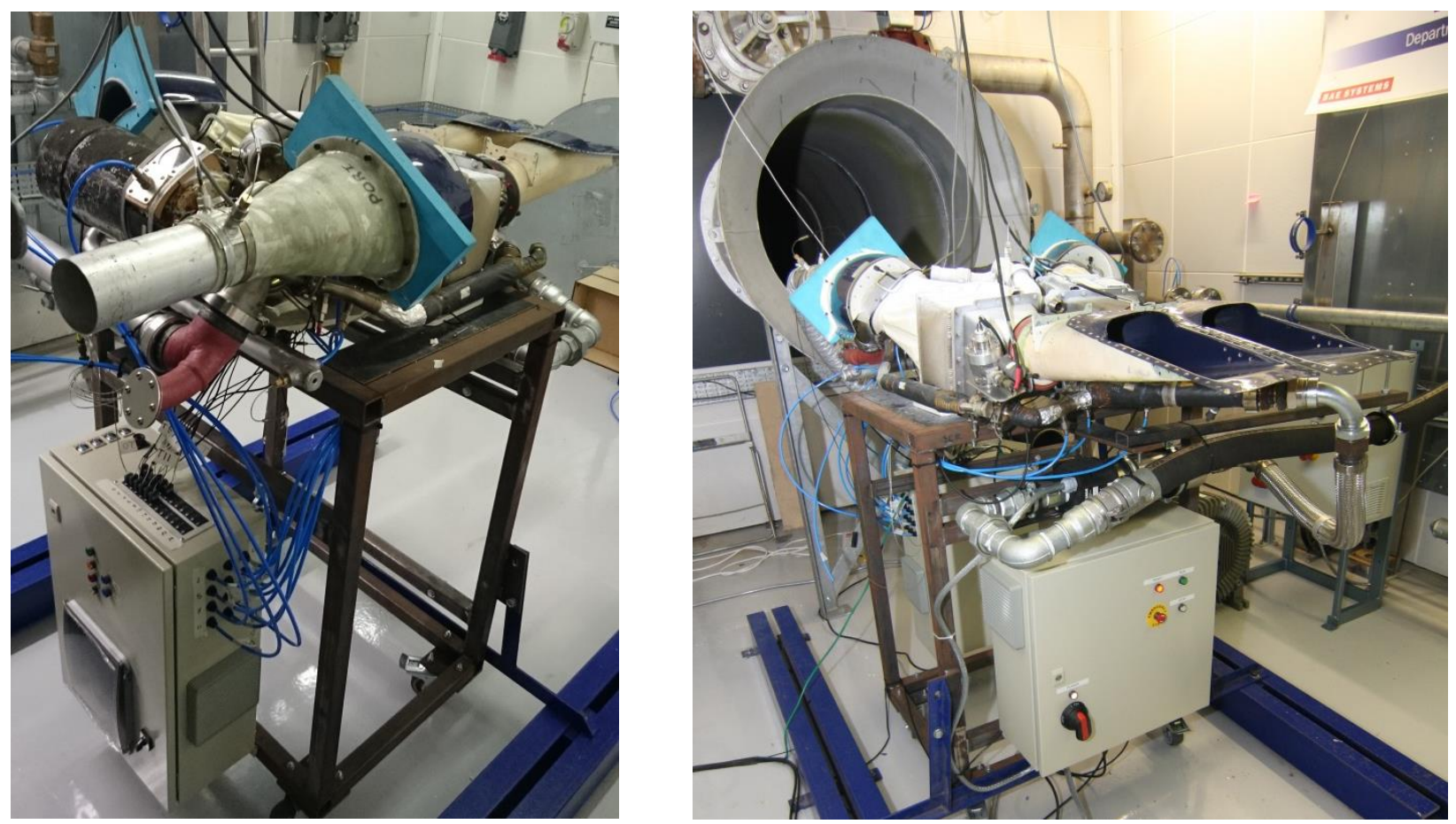

Figure 2. ECS Test Stand Installation.

(a) shows the front of the system; with ram air inlet and control / DAQ cabinet visible. (b) shows the rear of the system; with bleed air inlet, ram air exhaust and heater control cabinet visible.

Control and Data AcQuisition (DAQ) duties are performed by a National Instruments CompactRIO. This system is configured with individual 'modules' that perform dedicated input/output (IO) tasks, thus tailoring the system to the application in a cost-effective manner. Thermocouples are read by a module with an internal cold junction, and pressure transducers are used to generate voltage signals. TCV positions are measured with rotary potentiometers. Orifice plates are used to calculate mass flow. All instruments are calibrated in accordance with manufacturer recommendations.

The system is controlled over a part-time Internet Protocol (IP) link, and has the capability to run autonomously. Thermal stability in the ECS is recognised by the software, and defined by a temperature change rate in degrees Celsius per minute (Cmin-1) across several key locations. The instruments are sampled at $125 \mathrm{~Hz}$, appropriately filtered, and averaged over a period of $20 \mathrm{~s}$.

\section{Air Supply}

Figure 3 below describes the limits of the air supply available to the GTF. Humidity level is controlled constant by the air farm, and monitored by the DAQ.

\begin{tabular}{|l|l|l|l|}
\hline Component & Spec Aim & Method & Performance \\
\hline Bleed Air Compression & $\begin{array}{l}\text { Indefinite run time at } \\
0.3 \mathrm{kgs}-1 \\
\text { Absolute humidity } \\
5 \mathrm{gkg}-1\end{array}$ & $\begin{array}{l}\text { Piston air compressor } \\
\text { Desiccant drier } \\
\text { Receiver tanks } \\
\text { Closed-loop mechanical } \\
\text { air pressure control }\end{array}$ & $\begin{array}{l}368 \mathrm{~kW} \\
40 \mathrm{~m} 3 / 13 \mathrm{Bar}\end{array}$ \\
\hline Bleed Air Heating & $\begin{array}{l}\text { CAU inlet conditions } \\
\text { across all flight cases }\end{array}$ & $\begin{array}{l}\text { Electrical resistance } \\
\text { process air heater } \\
\text { PID control }\end{array}$ & $\begin{array}{l}36 \mathrm{~kW} \\
150 \mathrm{C} / 0.25 \mathrm{kgs}-1\end{array}$ \\
\hline Ram Air Flow & $\begin{array}{l}\text { HXS bleed air heat } \\
\text { transfer 15kW } \\
\text { High-altitude cruise \& } \\
\text { ground operation }\end{array}$ & $\begin{array}{l}\text { Side-channel blower } \\
\text { AC inverter speed control }\end{array}$ & $\begin{array}{l}5.5 \mathrm{~kW} \\
275 \mathrm{~m} 3 \mathrm{hr}-1 / 0.3 \mathrm{Bar}\end{array}$ \\
\hline
\end{tabular}

Figure 3. GTF Air Supply Specification 


\section{B. Performance Metrics}

The analysis performed in this report is primarily concerned with the thermodynamic first law, i.e. energy conservation. Due to the significant amounts of internal energy degradation involved in the passage of bleed air through the ECS, first law analysis is insufficient to fully describe the cost of the system to the aircraft. ${ }^{1-14}$ The analysis applied here uses data taken from an experimental rig, which takes account of the irreversibility present, if not quantifying it. This type of analysis as a means of comparing system effectiveness back-to-back in this case is sufficient.

A full entropy generation analysis has been conducted on the ECS from the data presented here; however the results have been omitted from the report. This is because second law analysis finds most use when optimising a design and its value is limited when deliberately introducing faults to a system which is known to have poor energy efficiency. ${ }^{15-20}$ The primary focus of this investigation is to identify whether the system can still operate within specification for a given fault in order to improve reliability, with efficiency as a secondary concern.

\section{Coefficient of Performance}

Coefficient of Performance (CoP) is a common measure of effectiveness for heat pumps and refrigeration devices. As the primary function of the ECS is to reduce the temperature of the working fluid, CoP finds common use in evaluation of its performance. The general form of $\mathrm{CoP}$ for a refrigeration cycle is given by: ${ }^{11}$

$$
\text { CoP }=\frac{\dot{Q}_{\text {out }}}{\dot{W}_{\text {in }}}=\frac{\text { Net useful heat transfer rate }}{\text { Total work consumption rate }}
$$

This definition is straightforward to apply when considering a traditional closed cycle, such as that used in a phase-change refrigeration unit. A mechanical work term is usually directly calculable (for example current draw by an electric motor), whilst the heat transfer rate is usually based upon the net result of changing or maintaining the temperature of a closed volume.

Where an ECS is concerned, it is less straightforward to define each constituent of the equation. The process of cooling bleed air is not a 'useful output' in itself; when that fluid is then used to remove quantifiable heat loads elsewhere. Meanwhile, the work consumption rate is equally hard to define as no direct mechanical power is supplied to the ECS. All of the fluid streams of interest are open, whereas usually a coolant working fluid would operate in a closed cycle. CoP as a measure of ECS effectiveness has very little to do with the energy cost to the aircraft as a whole.

For this investigation, the method to calculate CoP is given by:

$$
C o P_{S y s}=\frac{\dot{Q}_{S y s}}{\dot{W}_{S B}+\dot{W}_{S R}-\dot{W}_{E S y s}} \quad\left[C o P_{C y c}=\frac{\dot{Q}_{C y c}}{\dot{W}_{S C y c}+\dot{W}_{S R S}-\dot{W}_{E C y c}}\right]
$$

\begin{tabular}{|c|c|c|}
\hline Where & $\begin{array}{l}\operatorname{CoP}_{S y s} \quad \text { is } \\
\dot{Q}_{S y s} \\
\dot{W}_{S B} \\
\dot{W}_{S R} \\
\dot{W}_{E S y S}\end{array}$ & $\begin{array}{l}\text { Coefficient of Performance for the whole system } \\
\text { Heat rejection in bleed air } \\
\text { Work to compress and heat bleed air } \\
\text { Work to drive ram air through HXs } \\
\text { 'Work potential' pressure recovery available in exhaust fluid }\end{array}$ \\
\hline
\end{tabular}

This equation is applied to both the overall ECS at system level and to the cycle at component level ( $\left.C_{0} P_{C y c}\right)$. System CoP considers flow between SB and pack exhaust, whereas cycle CoP considers only the flow through CAU and HXS. The exhaust pressure recovery $\left(\dot{W}_{E}\right)$ term is included so that the internal energy remaining in the flow at ECS exhaust is quantified. This allows for the CoP calculation to account for the pressure loss across the system, which varies with bleed air inlet condition and TCV position.

Each of the terms in the CoP equation are calculated by the following methods. There is a desire to idealise the calculations as much as possible, so that any irreversibility effects associated with the process used to actually perform the work on the bleed air flow external to the ECS are neglected:

$$
\begin{gathered}
\{1\}: Q_{S y s}, Q_{C y c}: Q=\dot{m} \Delta h=\dot{m} C_{P} \Delta T \\
\{2\}: \dot{W}_{S B}, \dot{W}_{S C y c}, W_{E S y s}, W_{E C y c}: \dot{W}=\dot{m} C_{P} T_{A}\left[\left(\frac{P}{P_{A}}\right)^{\frac{\gamma-1}{\gamma}}-1\right]
\end{gathered}
$$




$$
\{3\}: \dot{W}_{S R}, \dot{W}_{S R S}: \dot{W}=\frac{\Delta P_{R} \dot{m}}{\rho}=\frac{\Delta P_{R} \dot{m} R T_{S R}}{P_{S R}}
$$

The temperature and pressure ranges seen throughout the cycle allow for air to be approximated as a perfect gas. ${ }^{21}$ The derivation of each equation above is taken from the following:

1. From the standard form of steady flow energy equation, neglecting changes in gravitational potential energy and fluid velocity where mechanical work done on or by the fluid is nil. ${ }^{21}$

2. From work done during isentropic compression for an open system. ${ }^{21,22}$ The same equation is used to quantify the exhaust fluid pressure recovery, by assuming that this is the maximum amount of work recoverable from the fluid during isentropic expansion.

3. From the power required to move an item with a force at a velocity, $P=F v$. The net force on the heat exchanger is easy to calculate accurately, given a significant pressure differential in the ram air stream.

\section{Performance Indicators}

Figure 4 shows how turbine-out temperature, total cycle pressure ratio and total bypass mass flow correlate to system CoP. These values are normalised, so as to allow side-by-side consideration. These parameters are referred to as performance 'indicators', as they share common linear trends with $\mathrm{CoP}$ and serve to quickly indicate how effective an ECS operating point is likely to be without deeper analysis. The term Aggregate Pack Exhaust Temperature (APET) is used to describe the mass-flow-weighted average exhaust temperature of the system (EE, $\mathrm{EC})$.

Total Bypass Mass Flow (TBMF) is a summation of the flows through the equipment and cabin bypass branches. Flow in these branches is not worked through a cycle, and a significant proportion of the internal energy in

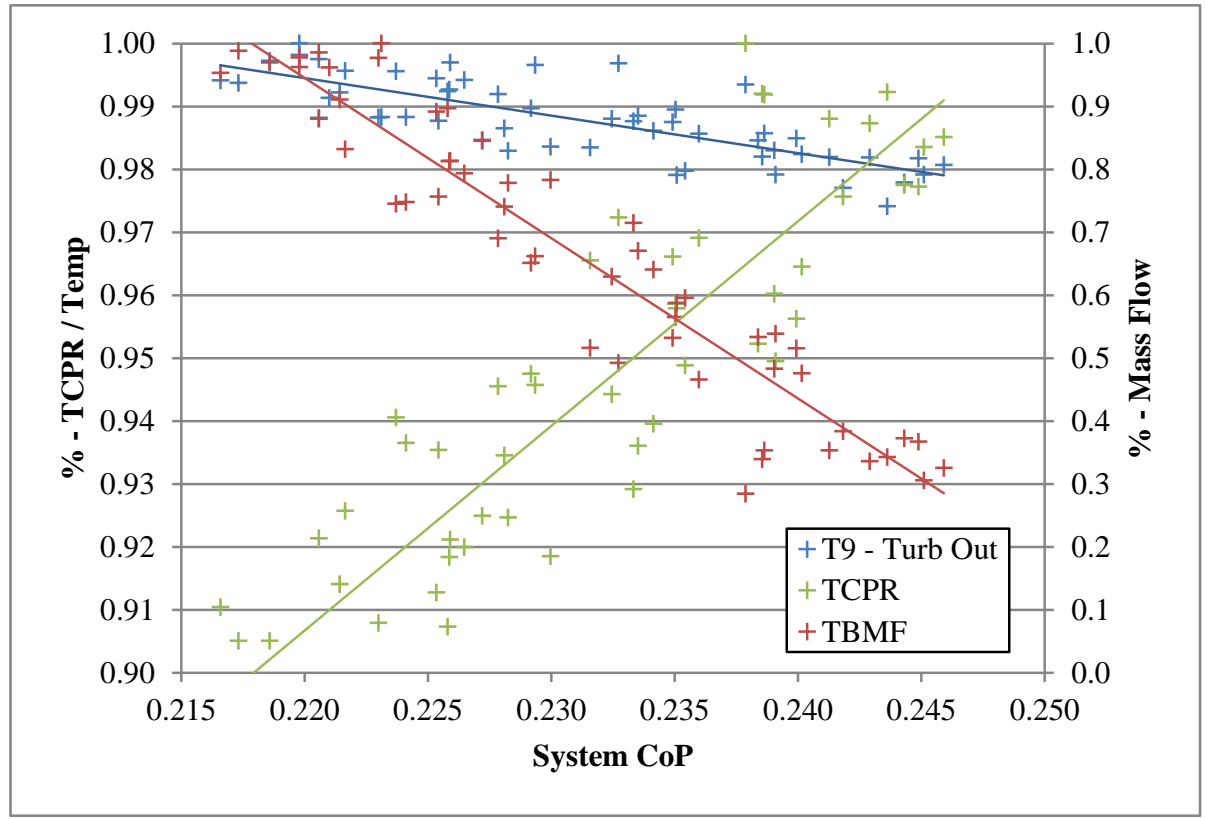

Figure 4. Performance Indicators against System CoP

the flow is dissipated to friction. Furthermore, imperfect mixing of the bypass and cycle flows (ME, $\mathrm{MC}$ ) is a further source of irreversibility. ${ }^{11}$

Total Cycle Pressure Ratio (TCPR) is the ratio between compressor-in and turbine-out pressure. It is a measure of the pressure energy converted to work in the turbine. Rather than considering turbine pressure ratio in isolation, the efficiency of the compressor and pressure drop across HXS also affects TCPR.

The temperature at turbine exhaust is always the lowest-temperature part of the cycle (instrumentation location 9). As the ECS primarily acts to remove heat from the aircraft, the lower the temperature fluid is delivered to the cabin, the higher the rate of heat rejection from the cabin for a fixed mass flow. Increasing TBMF essentially 'throttles' the cycle by reducing TCPR; meaning less work done by the cycle flow and less heat rejection to the ram air, and ultimately higher turbine-out temperature.

A strong linear correlation is shown between $\mathrm{CoP}$ and each of the three performance indicators, as shown by the trend lines in Figure 4. Analysis of the faults inserted in this investigation concentrate on the effects on these performance indicators, as often other factors can influence $\mathrm{CoP}$ and mask small amounts of degradation in system performance.

\section{Component Efficiency Maps}

The benefit to working with a legacy system is that a wealth of empirical documentation is available. The compressor and turbine have both been mapped for efficiency against flow parameter, pressure ratio and normalised shaft speed. Together, these parameters account for variations in flow temperature, pressure, density, mass flow and 
velocity. Originally, these maps would have been used to influence isentropic efficiency calculations, and with good accuracy. Now, the maps are used to analyse the effect of fault degradation on system performance.

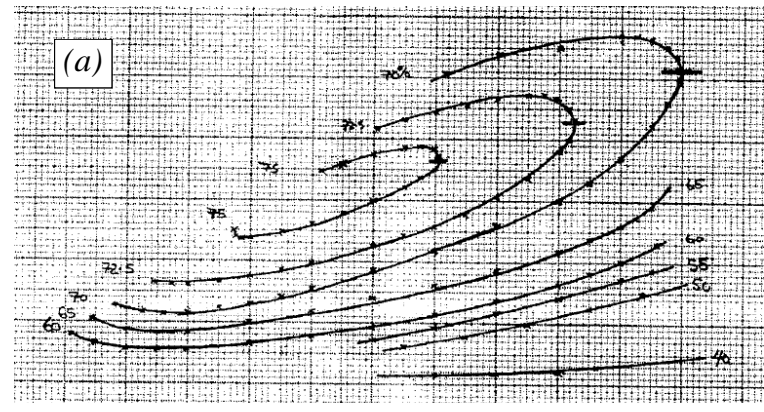

Figure 5. Empirical ECS Component Efficiency Maps.
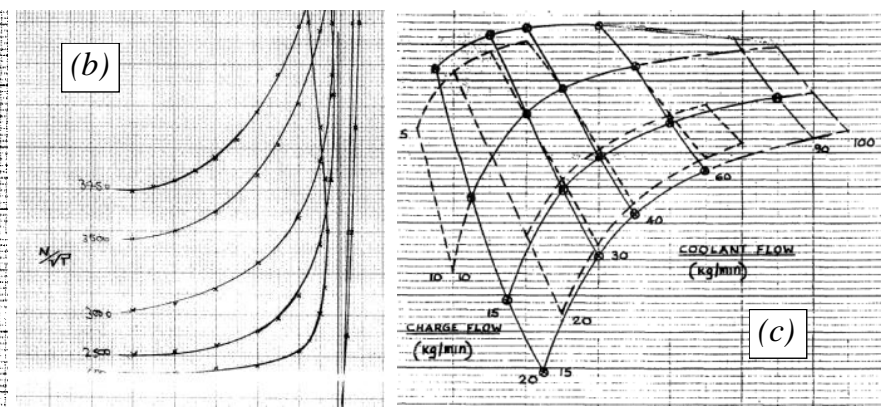

(a) compressor, (b) turbine, (c) heat exchanger

\section{Fault Injection Methods \& Test Plan}

The following tests are conducted on the ECS, based on those most likely to occur during operation:

- Bleed air blockage in:

$\circ \quad$ HXS (instrumentation location 7)

$\circ \quad$ WE (instrumentation location 11)

- TCV failure of CTCV, ETCV each in isolation

\section{Flight Case Specification}

Prior work on the complete installed system (including cabin and avionics bays and their associated performance) has identified one operating condition in particular as worst case scenario for the ECS. This is referred to as 'ground case heat soak', where the aircraft is parked outside for a number of hours or days in a hot environment with no cloud cover. The bulk temperature of the aircraft in this case is likely to reach in excess of 50C. Auxiliary systems are then started (power unit (APU), hydraulics and avionics), transferring more heat to the airframe. The ECS takes

\begin{tabular}{|l|l|l|l|}
\hline Fluid & Parameter & Unit & Nominal Value \\
\hline Bleed Air \\
$\begin{array}{l}\text { Cycle Inlet } \\
\text { (Comp.-in) }\end{array}$ & Temperature & $\mathrm{C}$ & 92 \\
\cline { 2 - 4 } & Pressure & BarA & 3.8 \\
\cline { 2 - 4 } $\begin{array}{l}\text { Ram Air Inlet } \\
\text { (HXS) }\end{array}$ & Temperature & kgs-1 & 0.175 \\
\cline { 2 - 4 } & Mass Flow & $\mathrm{C}$ & 42 \\
\hline $\begin{array}{l}\text { Conditioning } \\
\text { Air (System }\end{array}$ & Cabin Temperature & $\mathrm{kgs}-1$ & 0.170 \\
\cline { 2 - 4 } Exhaust) & Equipment Temperature & $\mathrm{C}$ & 15 \\
\cline { 2 - 4 } & Pressure & BarA & 1.6 \\
\hline
\end{tabular}
power from the APU and is tasked with rejecting these heat loads, as well as reducing the temperature of the cabin to a level that is habitable for the pilot. This case is the focus for many other areas of research on this system. ${ }^{23}$

The limiting factor for ECS performance at this case is ram air; at low mass flow rate and high temperature. This limits the heat rejection rate of the cycle and hence turbine-out temperature. When operating the system at this condition, the performance 'reserve' is generally at or close to nil (minimal-to-no TBMF). Therefore if the system can operate satisfactorily with a fault present at this case, it is likely to retain this functionality whilst in flight. Figure 6 quantifies the ground case heat soak, in terms of system inputs.

\section{Test Repeatability}

The requirement for the GTF bleed air delivery system to operate indefinitely is driven by the desire to replicate full flight profiles in real-time. A typical sortie for this type of aircraft will last between 60-120 minutes. Ensuring this capability allows the timing effects of the control system to fully develop and be analysed, as well as to ensure equilibrium in the temperature of the components and the ambient.

When taking the control software out of the equation, thermal equilibrium of less than $0.1 \mathrm{Cmin}-1$ across all measured gas temperatures is found within approximately 5 minutes for a small operational change. The control software works on a duty cycle of approximately $10 \%$ for ETCV, and $100 \%$ for CTCV. This eliminates the possibility of the valves both constantly moving to find equilibrium ('fighting' each other), but also means that the system can take upwards of $15 \mathrm{~min}$ to satisfy the same thermal equilibrium criteria, when a large change in ETCV position is required. 
The low temperatures generated at turbine exhaust are sensitive to both component and ambient temperature, due to minimal insulation at this location. Some of the data presented in this report is composed from several tests performed hours apart. Test variation means that some of these composite curves contain small anomalies.

\section{Blockage Testing}

Blockages are inserted into the bleed air path by means of an orifice plate sandwiched in the joint between two components. Whilst this method of replicating a blockage does not specifically degrade the performance of the affected component, its advantages are:

- Changes in pressure distribution through the cycle primarily affect the operation of CAU. Heat transfer in HXS, bypass flows and mixing in ME, MC are indirectly driven by the performance of CAU. Inserting an orifice plate to simulate a blockage affects the cycle pressure distribution.

- The size of the orifice is easy to quantify. Pressure directly up- and down-stream of the orifice is easy to measure.

- The failure can be repeated without risk of damage to the 'blocked' components.

The following tests are conducted:

- A blockage plate is installed at HXS-in (typical pressure 5.3BarA). Cabin temperature demand is swept. The test is repeated for a sweep of blockage per cent by area, in $10 \%$ increments.

- The testing is repeated for blockage plates installed at WE-in (typical pressure 1.7BarA).

\section{TCV Failure Testing}

The TCVs are butterfly type, driven by a geared motor. No positional feedback is given to the control software. Temperature control is achieved by applying a forward or reverse voltage to the motor dependent on whether the control temperature is above or below the setpoint. The TCVs operate across a wide range of temperatures, and fail at their current position rather than defaulting to one extreme of travel.

In order to describe the effect on cycle and system operation of a failed valve, the control system has been modified to allow manual position control on each or both valves simultaneously. The following tests are conducted:

- Manual position of both valves is swept to complete a 2D map of CTCV and ETCV position.

- Manual position of each valve is fixed in isolation, with automatic control retained at the 'healthy' valve. Cabin temperature demand is held constant whilst 'failed' valve position is swept. The test is repeated for a sweep of cabin temperature demand.

The resulting data allows two outcomes. A thermodynamic system profile is constructed, which shows the unrestricted capability of the components. By including partial effects of the control software, it is possible to discover which parts of the thermodynamic profile the installed system has the capability to reach.

\section{Results \& Analysis}

\section{A. Blockage Testing}

The figures below show how pressure and temperature propagate through the cycle for the system, under normal operation and with a blockage mid-cycle and post-cycle. The blockage is $90 \%$ by area in both cases, which is enough to severely decrease the performance of the system and to exaggerate the relative differences in the operation of the cycle across the three different scenarios. 


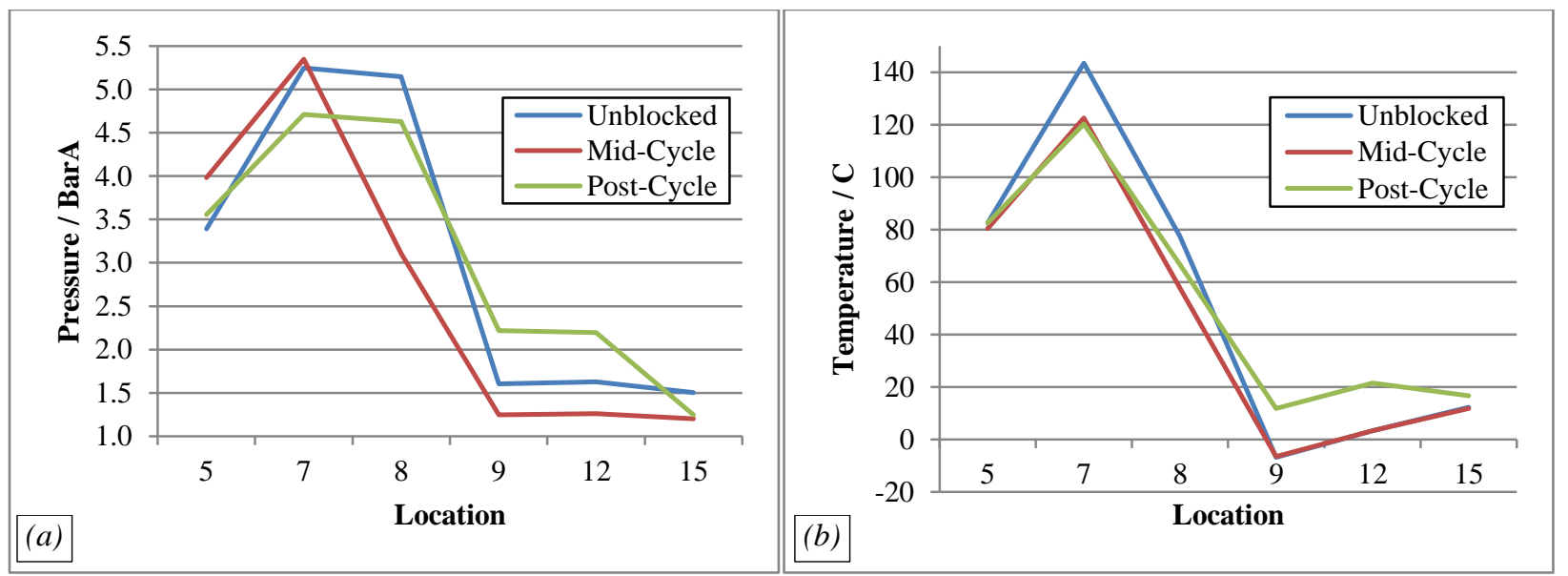

Figure 7. Cycle Blockage Comparison.

(a) shows absolute pressure, (b) shows temperature; against instrumentation location. The $x$-axis propagates through the cycle from compressor-in to equipment-and cabin-supply.

These figures allow qualitative analysis with respect to the $\mathrm{CoP}$ equation terms and performance indicators discussed earlier. The key features to examine are: turbine-out temperature, APET, TCPR, and exhaust pressure (as a measure of the $\dot{W}_{E}$ term in the CoP equation). General observations of these features are made below, and explored in greater detail in the subsequent sections. Figure 8 gives key system parameters for the three operating states.

\begin{tabular}{|l|l|l|l|l|l|}
\hline Parameter & Symbol & Unit & Unblocked & Mid-Cycle & Post-Cycle \\
\hline CTCV Posn & & $\%$ & 34 & 27 & 0 \\
\hline ETCV Posn & & $\%$ & 19 & 0 & 0 \\
\hline T9 - Turb Out & & $\mathrm{C}$ & -6.7 & -6.5 & 11.8 \\
\hline T12 - Equip Feed & & $\mathrm{C}$ & 3.3 & 3.3 & 21.5 \\
\hline T15 - Cabin Feed & & $\mathrm{C}$ & 12.3 & 11.8 & 16.6 \\
\hline TCPR & & & 2.11 & 3.19 & 1.60 \\
\hline Bleed Air Mass Flow & & $\mathrm{kgs}-1$ & 0.177 & 0.103 & 0.136 \\
\hline Cycle Mass Flow & & $\mathrm{kgs}-1$ & 0.165 & 0.101 & 0.136 \\
\hline Bypass Mass Flow & & $\mathrm{kgs}-1$ & 0.012 & 0.002 & 0 \\
\hline CAU Shaft Power & & $\mathrm{kW}$ & 12.4 & 5.7 & 6.7 \\
\hline HXS Bleed HT & & $\mathrm{kW}$ & 11.3 & 6.8 & 7.5 \\
\hline HXS Bleed dT & & $\mathrm{C}$ & 67.3 & 66.0 & 54.9 \\
\hline Cycle Heat Rejection & $\dot{Q}_{C y c}$ & $\mathrm{~kW}$ & 15.2 & 9.1 & 9.9 \\
\hline Bleed Heat Rejection & $\dot{Q}_{S y s}$ & $\mathrm{~kW}$ & 13.3 & 7.6 & 9.1 \\
\hline Bleed Power & $\dot{W}_{S B}$ & $\mathrm{~kW}$ & 229 & 138 & 174 \\
\hline Cycle CoP & $C o P_{C y c}$ & & 0.28 & 0.19 & 0.33 \\
\hline System CoP & $C_{S y s}$ & & 0.21 & 0.15 & 0.18 \\
\hline
\end{tabular}

Figure 8. Cycle Blockage Key Parameter Comparison

- A blockage in the system reduces the pack exhaust pressure, which in turn drives lower bleed air mass flow. In most cases lower mass flow has the effect of increasing the CoP of the system due to the difference in magnitude between input energy and useful output, however the presence of a blockage negates this.

- A significant blockage in the low-pressure part of the cycle leads to increased turbine-out temperature. This is due to the reduced total pressure ratio of the cycle, and corresponding drop in HXS heat transfer and CAU shaft power.

- Reduced cycle performance when a post-cycle blockage is present means that the ECS can no longer control its exhaust temperature (both TCVs closed). The demanded cabin temperature of $15 \mathrm{C}$ cannot be achieved in this case. This is seen to a lesser extent for the mid-cycle blockage.

American Institute of Aeronautics and Astronautics 
- A blockage in the high-pressure part of the cycle does not in isolation increase the turbine-out temperature. Reduced performance in the compressor and HXS is partly accounted for by the increased total pressure ratio of the cycle.

- The expansion of the bleed air across the post-cycle blockage does not yield a significant drop in temperature, as it does when performed in the turbine. This is because the internal energy is dissipated to friction, rather than being recovered and recycled back into the flow.

- Cycle mass flow is significantly less with a mid-cycle blockage than with a post-cycle blockage. Despite this, both HXS and cycle heat transfer are of similar magnitude to the post-cycle case. This can be explained by the high total pressure ratio.

In the case of a blockage, system CoP is reduced. This can be related to degradation of one or more performance indicators in each case. The complete elimination of bypass flow in the case of a post-cycle blockage means system $\mathrm{CoP}$ is relatively high, as all of the bleed air is worked through a cycle. In the case of a mid-cycle blockage, the cycle's ability to retain turbine-out temperature means that bypass flow must be used to drive APET. System CoP is lowest for this case, due to the heightened effect of the bypass flow around a blocked cycle. This is shown in the difference between cycle and bleed air heat rejection.

Cycle CoP is high in the case of the post-cycle blockage, due to the high turbine-out pressure which is directly caused by the blockage. This signifies the amount of internal energy remaining in the flow - in this case it is mainly dissipated across the blockage, hence the reduction in CoP between the cycle and the system.

All of the analysis above ignores the fact that a lower conditioning air mass flow is delivered to the cabin when a blockage is present in the system. Whilst certain elements of the system or cycle may appear to perform better in the case of a blocked flow path, this can almost always be attributed to the fact that the mass flow of the system is reduced. A smaller mass flow means less power draw from the bleed air supply.

The following analysis concerns the operation of the system under much smaller relative blockages. The trends discovered above are still present according to the location of the blockage, but in many cases their effects are much more difficult to witness due to small magnitudes. The blockages only start to take significant effect when cycle mass flow falls below approximately $75 \%$ of the unblocked state.

\section{Post-Cycle Blockage Analysis}

The figures below show plots of increasing cycle blockage, for TCPR and turbine-out temperature (T9) against APET.

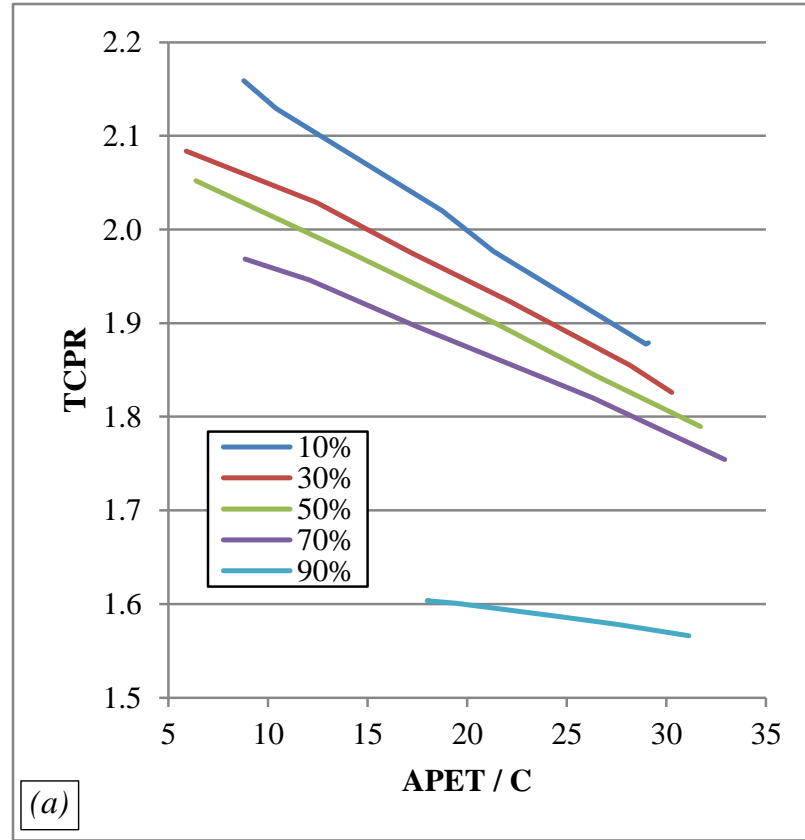

Figure 9. Performance Indicators for Post-Cycle Blockage. temperature varies; when a blockage is applied post-cycle. Note how the achievable APET range is limited with the inclusion of a significant blockage. Blockages up to approx. $50 \%$ cause minimal performance degradation.

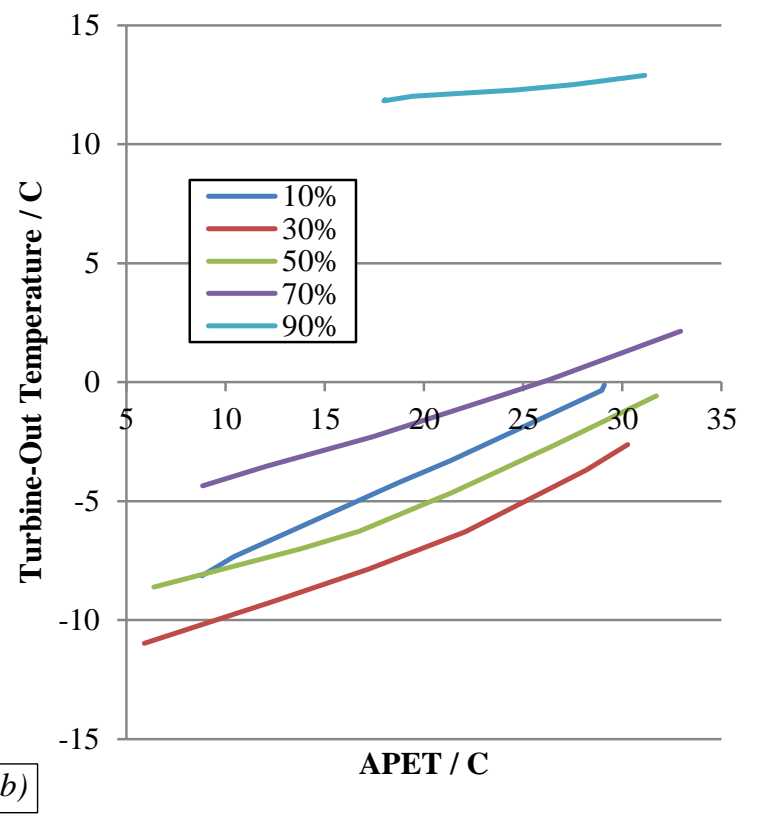

(a) shows how TCPR falls, (b) shows how turbine-out 
Figure 9 above is analysed below:

- The range of aggregate exhaust temperatures achievable is limited with the inclusion of a low pressure blockage. This is shown by the $\mathrm{x}$-axis location of the left-hand end of the curve. Turbine-out, and hence equipment feed temperature, is severely affected with any blockage greater than approximately $50 \%$ by area.

- Turbine-out temperature exhibits a local minimum when a blockage of approximately $30 \%$ by area is applied. This behaviour is caused by the effect of the back pressure induced by the blockage on the cycle, which in turn affects CAU efficiency. This is discussed further below.

- TCPR falls consistently with increasing blockage, for a given pack exhaust temperature. This leads to reduced conditioning air mass flow and indicates poor system operation (performance indicators, Figure 4).

A significant blockage experienced post-cycle at low pressure is likely to have a noticeable effect on the performance of the ECS, mainly because of the system's inability to generate low pack exhaust temperatures. The system can still operate satisfactorily with a small (up to approximately $50 \%$ by area) blockage in this location. The degradation in turbine-out temperature causes the TCVs to close in order to maintain the demanded pack exhaust temperature, in turn reducing the overall mass flow of the ECS. This failure mode is audible.

\section{Mid-Cycle Blockage Analysis}

Figure 10a below is a repeat of Figure $9 \mathrm{~b}$ above (turbine-out temperature against aggregate pack exhaust temperature, for a range of blockages), but for a mid-cycle blockage at high pressure. Figure 10b depicts heat transfer and CoP parameters against blockage per cent by area, for a single cabin temperature demand of $15 \mathrm{C}$.

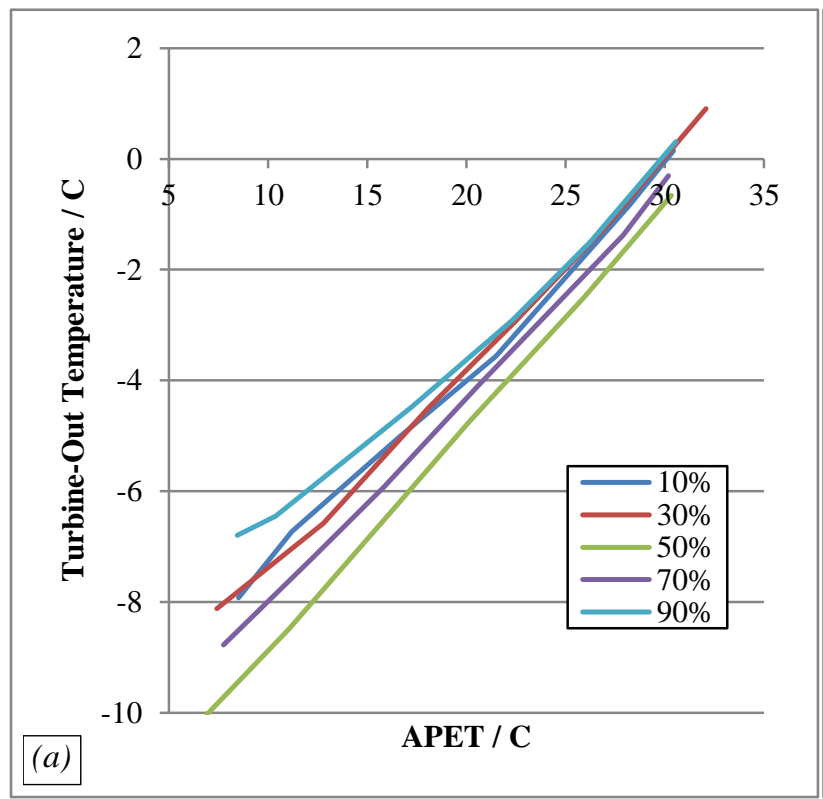

Figure 10. Performance Indicators for Mid-Cycle Blockage.

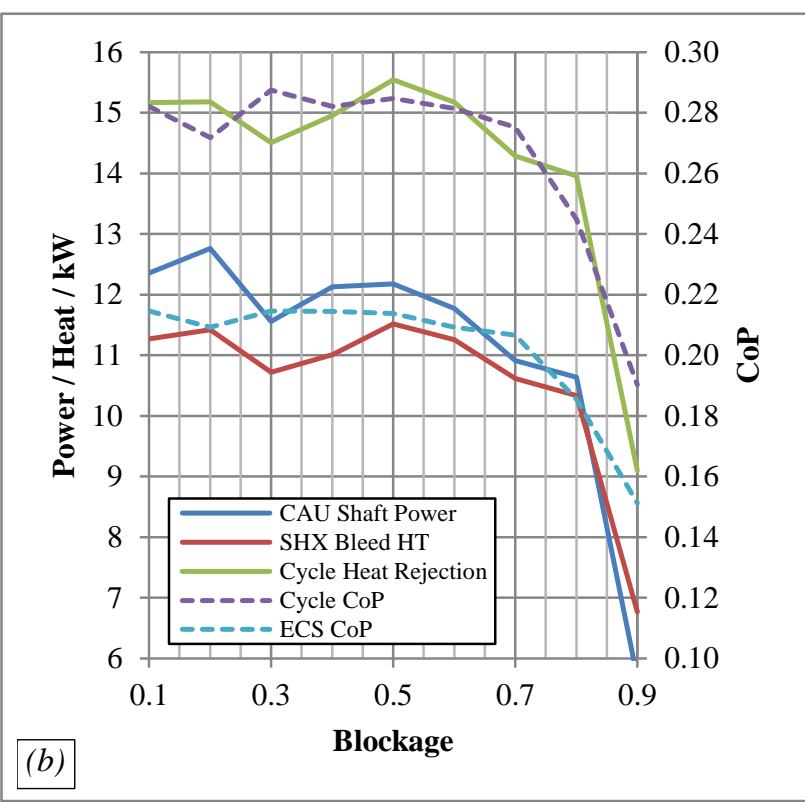

(a) shows how turbine-out temperature is insensitive to until significant blockage of $75 \%$.

Figure 10 above is analysed below:

- The range of aggregate pack exhaust temperatures achievable is not limited by the inclusion of a high pressure blockage. The turbine-out temperature for a given aggregate pack exhaust temperature suffers a small amount at low exhaust temperatures and high blockages. This is not drastic enough to affect equipment or cabin supply temperatures.

- Turbine-out temperatures in all cases are almost within the bounds of test repeatability.

- The operation of the cycle, when measured according to performance indicators and CoP, remains essentially unaffected below approximately $75 \%$ blockage by area. Total cycle pressure ratio follows this same trend.

- The drop in performance experienced when more than $75 \%$ blockage is applied is attributed to severely reduced bleed air mass flow.

The net result is a system which is highly insensitive to a blockage mid-cycle at high pressure. 


\section{CAU Efficiency Comparison}

Figure 11 below shows how compressor and turbine efficiency varies with blockage proportion and location. This serves as both a comparison between location of blockage, and an explanation of why the system reacts to the blockage in the way shown above.

Observations from this graph are given below:

- Neither compressor nor turbine efficiency are affected by a mid-cycle blockage until approximately $70 \%$ by area. Compressor efficiency falls steeply after this point, due to increasing compressor-in and -out pressures but decreasing pressure ratio. This helps to explain why cycle performance is retained until approximately $75 \%$ blockage.

- For a post-cycle blockage, compressor efficiency falls. This is due to decreasing flow through the machine rather than decreasing pressure ratio.

- Increasing the back pressure on the turbine increases its efficiency, up to a point. This is because of the inherent difficulties in efficiently expanding a compressed fluid. Applying a back pressure to the machine means that it may convert more of the internal energy in the fluid to useful work output, bringing it closer to a perfect isentropic process approximation.

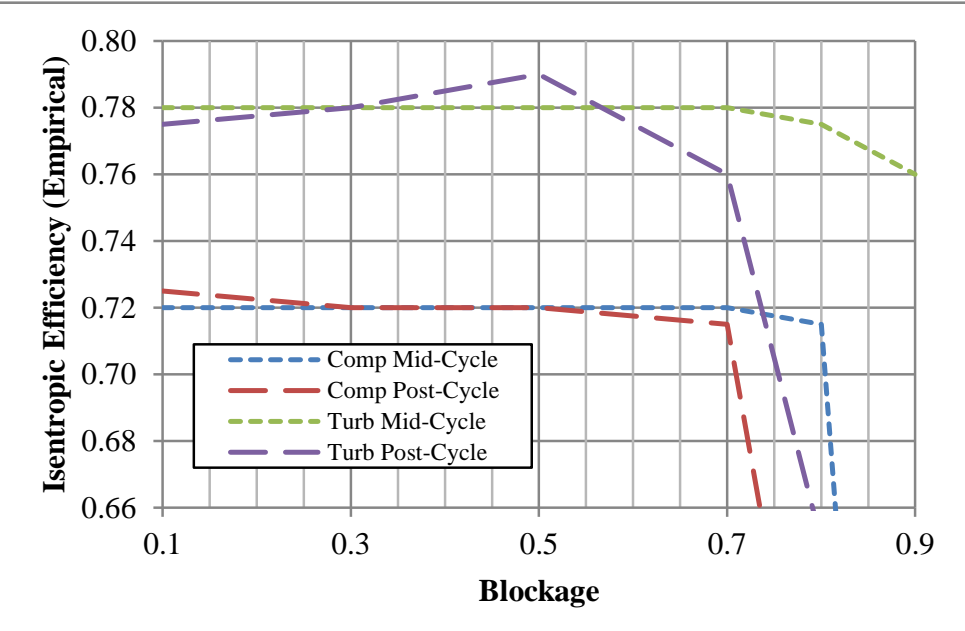

Figure 11. CAU Efficiency against Cycle Blockage

The discovery that turbine efficiency increases with a moderate application of back-pressure explains why turbine-out temperature peaks (low) when a small blockage is applied to the exhaust of the turbine. Figure 8 shows how cycle CoP increases with a post-cycle blockage, but also how this gain in efficiency is wasted by the low-pressure flow through the blockage. The current system could in theory be improved by adding a second expander device in the same location as the simulated blockage, at turbine exhaust. The improvement would be twofold: first by improving the expansion efficiency in the existing turbine, and second by increasing the power supplied to the compressor.

This finding agrees with the theoretical work conducted by Conceição, et al. ${ }^{24}$; that predicts a bootstrap ECS with two expansion stages to be $5 \%$ more efficient at a cruise condition and $90 \%$ more efficient during a ground case, than a system with a single expansion stage. Even though the efficiency gain found in the turbine is only $2 \%$, the net result is an improvement in turbine-out temperature by up to 5C (Figure 9b). Implementing this finding by design would realise further improvements.

\section{Blockage Testing Conclusion}

A blockage in the bleed air path of the system will not drastically affect its performance until cycle mass flow falls below approximately $75 \%$ of its unblocked state. This occurs at approximately $60 \%$ by area for a low pressure blockage and approximately $75 \%$ by area for a high pressure blockage. The capability of the cycle to overcome a blockage, in terms of turbine-out temperature, is related to the total pressure ratio of the cycle. Therefore, a low pressure blockage post-turbine has a more detrimental effect on system performance than a mid-cycle blockage at high pressure.

\section{B. TCV Position Testing}

The two following figures describe the control system and thermodynamic responses to varying TCV positions respectively. Figure 12a shows multiple curves for varying cabin delivery temperatures against TCV positions, which is a purely thermodynamic response of the system. Figure $12 \mathrm{~b}$ shows multiple curves for varying ETCV positions against pack exhaust temperatures over the control limits of the ETCV, which shows how the control software drives the ECS.

Figure 12a shows the possible combinations of valve position that could be used to generate a cabin temperature, ignoring the variation in equipment temperature. Figure $12 \mathrm{~b}$ then shows which portion of the total possible range the control system actually uses, by restricting equipment temperature to the limits on the $\mathrm{x}$-axis. For 
example, a cabin temperature demand of 20C would require ETCV position of 5-20\% in order to maintain equipment temperature specification. This would limit the attainable portion of the 20C curve in Figure 12a to these limits on the $\mathrm{x}$-axis.

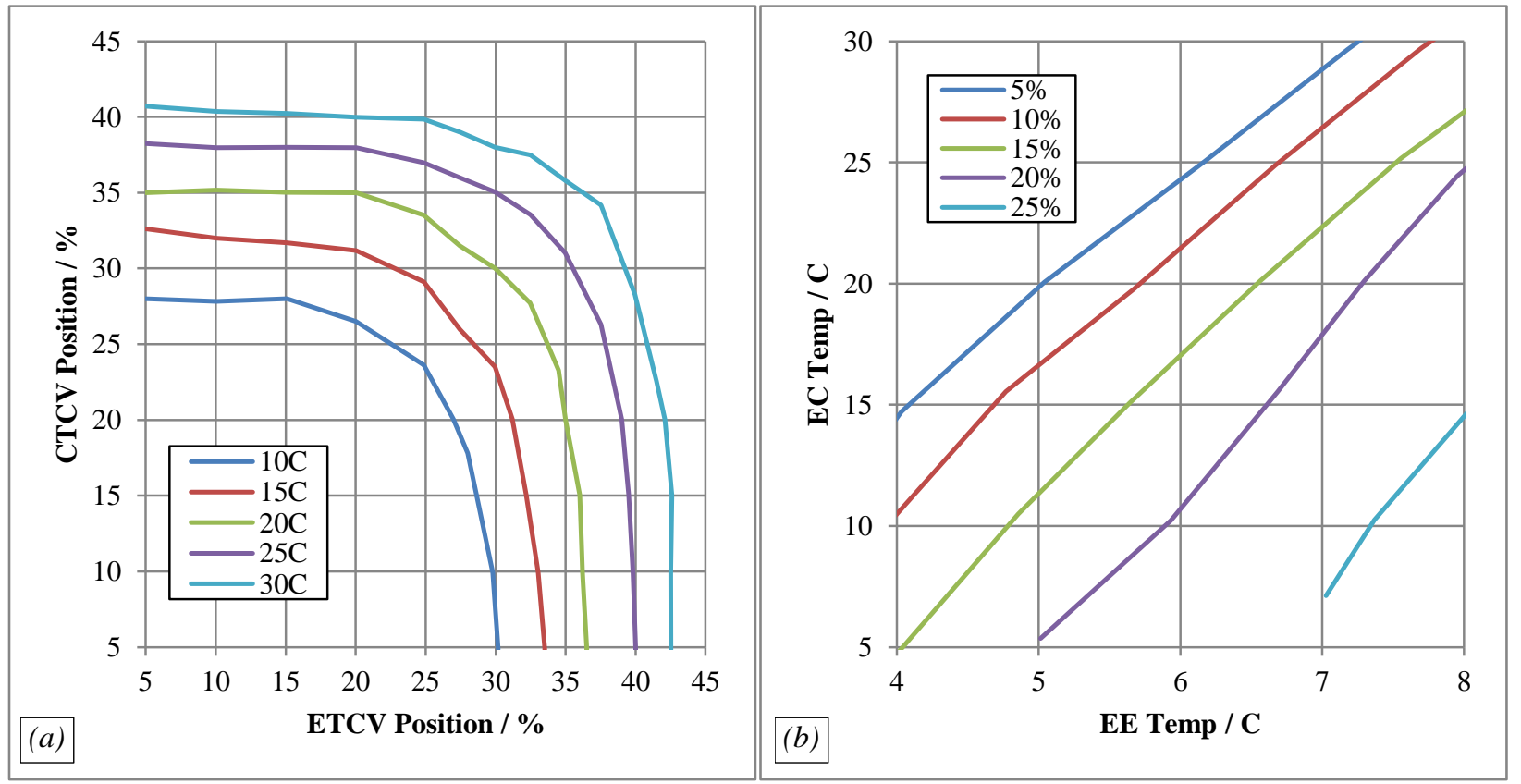

Figure 12. System Response to TCV Position.

(a) shows constant cabin-exhaust (EC) temperatures for a sweep of both TCVs, (b) shows equipment- and cabin-exhaust temperature relationships for fixed ETCV position curves.

Observations from this part of the testing are made below. Firstly, on the thermodynamic characteristics of the system:

- A given cabin delivery temperature is achievable with any combination of TCV positions along a constanttemperature curve in Figure 12a.

- There is little difference in the position required of each TCV in isolation to attain the same pack exhaust temperature. The difference arises through the pressure drop across WE.

- In the event of a valve failure, consider constant temperature curves that intersect the line drawn perpendicular to the axis of the failed valve at the point of failure in Figure 12a. These cabin temperatures are theoretically still attainable. For example, if CTCV fails at $35 \%$, cabin delivery temperatures of $20 \mathrm{C}$ and above are attainable.

- A change in inlet conditions alters the values seen on the graph axes, but does not change the relative trends of the curves plotted.

Comments on the effects of the control software:

- The control system drives to the lowest possible ETCV position for the demanded cabin temperature, in order to fulfil equipment delivery temperature requirements. ETCV will only move if equipment temperature falls out of spec, which is defined by the x-axis limits in Figure 12b.

- In the event of CTCV failure, ETCV position is not influenced by the cabin delivery temperature. Therefore, the system loses control of cabin delivery temperature, and delivers the minimum available for that valve position based on equipment delivery temperature.

- Figure $12 \mathrm{~b}$ shows that if ETCV fails at any point in its usual operating range (below approximately $30 \%$ ), it is unlikely that the failure would be identifiable, as cabin temperature control is retained. If ETCV fails at around 25\%, equipment temperature is only in spec at low cabin temperatures. If ETCV fails much above this point, the curve lies outside of the x-axis limits, and therefore equipment temperature is out-of-spec irrespective of cabin temperature.

The TCVs theoretically allow for redundancy in pack exhaust temperature control. In reality however; an ETCV failure will not be compensated for, and a CTCV failure will instantly cause the system to lose its ability to accurately condition the cabin. This behaviour is resultant of the age of the system; it was designed before microprocessor-driven control strategies were cost-effective to implement. 


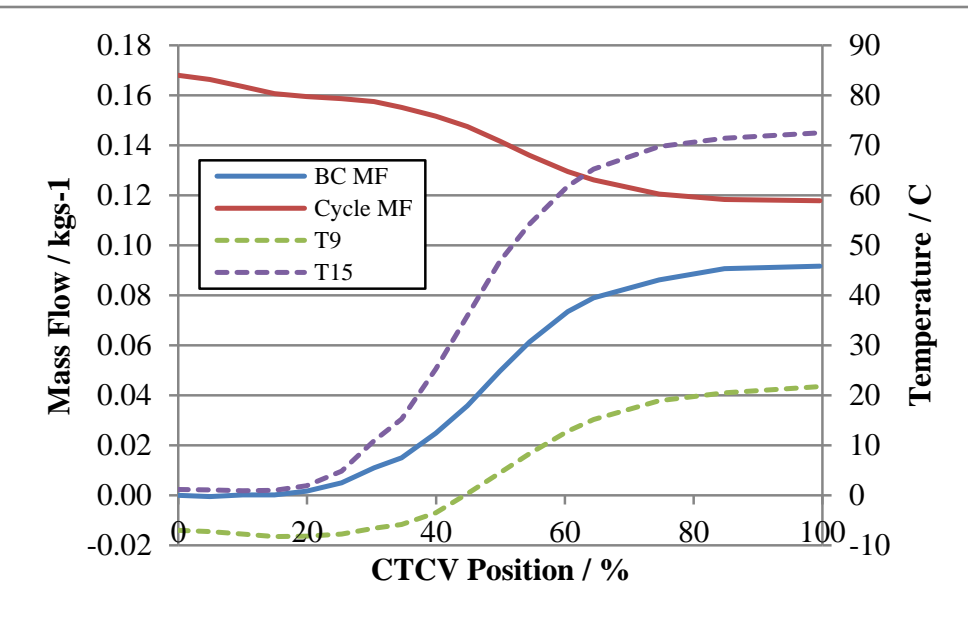

Figure 13. System Response to TCV Sweep

The system is highly sensitive to TCV position, where a change of $10 \%$ full travel yields a 20C difference in pack exhaust temperature. It is vital that pack exhaust temperature control is retained, due to the large and varying heat loads placed on the cabin. The sensitivity of the TCVs is explained by their geometry; Figure 13 shows how mass flow through the TCV varies with position.

Another interesting trend from this figure is how turbine-out temperature finds a local minimum with a small amount of cycle bypass. Other data from the same test shows that CoP and system entropy generation follow similar trends. It is thought that this is due to the effect of changing the back pressure on the cycle, in much the same way that a small post-cycle blockage does. The net effect is an improvement in CAU efficiency. Note also how the relief of pressure across the cycle reduces the cycle mass flow without increasing bypass mass flow.

\section{TCV Testing Conclusion}

The thermodynamic performance of the system is directly related to the percentage of cycle bypass air flow. The hardware architecture of this particular ECS allows either of two TCVs to almost equally regulate the turbineout and pack exhaust temperatures, with little influence on system performance / efficiency dependent on which valve is used. Depending on the position of the valve at the point of failure however, the pack exhaust temperature will be limited in range.

The control architecture of this particular system means that it is comfortably able to mask a failure of one valve (ETCV) but not the other (CTCV). This is due to sensor positioning and the path of signals within the control system. Whilst the failure can be masked, little can be done to identify or rectify it. If the software was redesigned to account for aggregate pack exhaust temperature in the positioning of both TCVs, the robustness of the system would be significantly improved.

\section{Conclusions}

\section{A. Final Remarks}

It is important to assess the presented results with the recollection that all of the testing was performed at a low bleed power condition for the ECS, partly due to GTF operational constraints and partly due to a requirement to investigate performance at ground case heat soak. Whilst this condition has a low power demand, it is conversely at one extreme of the operating envelope of the system. Any failure here that results in a degradation of the extraction of temperature from the bleed air is likely to propagate along the bleed air flow path to the cabin and equipment conditioning sub-systems. In operation, this particular ECS is limited by its capacity to cool the cabin from a high temperature ground heat soak case, where an increase in pack exhaust temperature would lead to an inability of the system to provide a safely inhabitable environment for the pilot. ${ }^{23}$

The calculated performance / efficiency of the system is universally low, independent of how this calculation is derived. These measures are also insensitive to how the cycle is driven or regulated. The interplay between HX heat extraction and CAU pressure recovery leads to a cycle that is essentially self-regulating, and which delivers a broadly similar turbine-out temperature regardless of bleed air inlet condition during normal operation. These features combined mean that any small change in the performance of one individual component is not likely to significantly affect the performance of the whole. Equally, any failure that affects turbine-out temperature will quantifiably (if not catastrophically) degrade the performance of the system.

The investigated failures are only likely to make themselves known during operation of the system where the turbine-out temperature is delivered directly to the cabin without bypass regulation, for example during ground case heat soak. It should be noted that the majority of flight cases require the TCVs to operate at a position to which pack exhaust temperature is highly sensitive; therefore the control system will account for most degrading-type failures. 
This conclusion in itself identifies why bootstrap-style air-cycle ECS finds use in so many modern highperformance applications, despite its inherent lack of energy efficiency. The cycle, through a degree of selfregulation, is able to overcome variations in operating conditions with minimal direct control intervention. This allows the system to maintain a relatively constant level of performance irrespective of harsh and varied operating conditions, and to fail safe under almost any circumstance.

During even an extreme mode of operation such as the ground case explored in this report, where the system is very near to the limit of its specification, the performance of the cycle is surprisingly insensitive to the majority of failures that it is likely to experience in operation. However, the failure of the CTCV will almost certainly and instantly render this particular ECS inoperable. The pack exhaust temperature is most sensitive to a change in the position of this valve over any other failure or inlet condition, and it is perhaps the only component which is both likely to fail and has no redundancy in this system configuration.

\section{B. Experimental Conclusions}

The experimental work conducted is summarised by the following:

- The performance of the bootstrap air cycle is insensitive to moderate bleed air blockages, where cycle mass flow does not fall below approximately $75 \%$ of that during normal operation. Blockages at low pressure are more detrimental to cycle performance than blockages at high pressure. The cycle and/or control system will self-regulate around most degrading-type faults.

- The bootstrap ECS is more resilient to faults in terms of its thermodynamic behaviour, than when installed in an aircraft and subject to regulation by a separate control system.

- This particular system is most sensitive to a failure at one bypass valve. The hardware allows partial redundancy of this valve, but the control system does not.

\section{Acknowledgements}

This project is co-funded by: the Engineering and Physical Sciences Research Council (EPSRC) UK, BAE Systems, and Loughborough University. The authors would like to thank the engineering staff at BAE Systems Warton and Brough for their support and guidance.

\section{Bibliography}

1 Dieckmann, R. R., Improved Reliability and Maintainability for Fighter Aircraft Environmental Control Systems, SAE International, 1988, 10.4271/880999.

2 Jones, A. B., and Chen, R., "Experimental Assessment of Vapour Chamber Heater Spreader Implementation in Avionic Cooling," 53rd AIAA Aerospace Sciences Meeting, American Institute of Aeronautics and Astronautics, 2015.

3 Halski, D., "FLASH Flight Control Systems," 1997, 10.4271/975626.

4 Sprouse, J. G., "F-22 Environmental Control/Thermal Management System Design Optimization for Reliability and Integrity - A Case Study," 1996, 10.4271/961339.

5 Karpenko, M., and Sepehri, N., "Hardware-in-the-loop simulator for research on fault tolerant control of electrohydraulic actuators in a flight control application," Mechatronics, vol. 19, Oct. 2009, pp. 1067-1077, 10.1016/j.mechatronics.2009.01.008.

6 Sprouse, J. G., “F-22 ECS/TMS Qualification Test Program Overview,” 1997, 10.4271/972261.

7 Ashford, R., and Brown, S., F-22 Environmental Control System/Thermal Management System (ECS/TMS) Flight Test Program - Downloadable Constants, an Innovative Approach, SAE International, 2000, 10.4271/200001-2265.

8 Letlow, J. T., and Jenkins, L. C., “Development of an Integrated Environmental Control System,” 1998, $10.4271 / 981544$.

9 Scott, M., Development of a Realistic, Automated, \& Efficient Reliability Development Growth Test for a Large, Distributed, Environmental Control System, SAE International, 1999, 10.4271/1999-01-2165.

10 Ryan, S. K., F-15 Environment Control System Improvements, SAE International, 1990, 10.4271/901235.

11 Bejan, A., Advanced Engineering Thermodynamics (Second Ed.), New York: John Wiley \& Sons, 1997, ISBN 0471148806.

12 Kotas, T. J., The Exergy Method of Thermal Plant Analysis, London: Butterworths, 1985, ISBN 0408013508 .

13 Borel, L., and Favrat, D., Thermodynamics and Energy Systems Analysis, Boca Raton, FL: Taylor \& Francis, 2010, ISBN 9781439835166. 
14 Moran, M. J., Availability Analysis: a Guide to Efficienct Energy Use, Englewood Cliffs, NJ: Prentice-Hall, 1982, ISBN 013054874X.

15 Ordonez, J., and Bejan, A., "Minimum power requirement for environmental control of aircraft," Energy, vol. 28, Oct. 2003, pp. 1183-1202, 10.1016/S0360-5442(03)00105-1.

16 Vargas, J. V. C., and Bejan, A., "Integrative thermodynamic optimization of the environmental control system of an aircraft," International Journal of Heat and Mass Transfer, vol. 44, Oct. 2001, pp. 3907-3917, 10.1016/S0017-9310(01)00033-3.

17 Vargas, J. V. C., and Bejan, A., "Thermodynamic optimization of finned crossflow heat exchangers for aircraft environmental control systems," International Journal of Heat and Fluid Flow, vol. 22, Dec. 2001, pp. 657665, 10.1016/S0142-727X(01)00129-1.

18 Buckingham, R. D., Helicopter Cooling, Air Cycle/Vapor Cycle Trade-Offs, SAE International, 1984, $10.4271 / 840942$

19 Rosenbush, F. M., ECS Schemes for All Electric Airliners, SAE International, 1982, 10.4271/820870.

20 Ganev, E., and Koerner, M., "Power and Thermal Management for Future Aircraft," 2013, 10.4271/201301-2273.

21 Rogers, G. F. C., and Mayhew, Y. R., Engineering Thermodynamics: Work and Heat Transfer : SI Units, Longman Scientific \& Technical, 1992, ISBN 0582045665.

22 NASA, "Compressor Thermodynamics," Beginner's Guide to Propulsion Available: https://www.grc.nasa.gov/www/k-12/airplane/compth.html.

23 Jones, A. B., Childs, T., Chen, R., and Murray, A., "Thermal Sensitivity Analysis of Avionic and Environmental Control Subsystems to Variations in Flight Condition," 54th AIAA Aerospace Sciences Meeting, San Diego, CA: American Institute of Aeronautics and Astronautics, 2016, pp. 1-15.

${ }_{24}$ Conceição, S. T., Zaparoli, E. L., and Turcio, W. H. L., Thermodynamic Study of Aircraft Air Conditioning Air Cycle Machine: 3-wheel × 4-wheel, SAE International, 2007, 10.4271/2007-01-2579. 